Jurnal Widya Sastra Pendidikan Agama Hindu, Vol 4, No. 2, 2022

ISSN: 2656-7466

\title{
KEUNIKAN CANDI BUDHA DAN UPAYA PELESTARIANNYA
}

\author{
Ketut Suka \\ ketutsuka382@gmail.com \\ I Wayan Gara \\ iwayan.gara@gmail.com
}

\section{ABSTRAK}

Penelitian ini bertujuan untuk mengetahui sejarah penemuan Candi Buddha Kalibukbuk, proses Pemugaran dan Keunikan Candi Budha Kalibukbuk, serta untuk mengetahui peran masyarakat dalam upaya menjaga kelestarian Candi Budha Kalibukbuk.

Penelitian ini dilakukan pada Candi Budha Kalibukbuk yang berlokasi di Desa Kalibukbuk, Banjar Dinas Kalibukbuk, dengan observasi dan wawancara yang mendalam baik terhadap pemilik lokasi Candi Budha Kalibukbuk, penjaga Candi Budha Kalibukbuk serta masyarakat disekitar Candi Budha Kalibukbuk dan selanjutnya data dianalisis dengan memproses temuan penelitian yang telah ditranskripkan melalui proses refleksi data, yaitu data dikumpulkan dan disaring dan kemudian disusun lagi, dipaparkan, diverifikasi atau dibuat suatu kesimpulan.

Hasil penelitian menunjukkan beberapa hal : (1) Penemuan Candi Kalibukbuk bermula pada tahun 1991, kemudian proses berlanjut lagi saat seorang warga bernama I Nengah Mawa pada tahun 1994 saat menguras sumur terjadi longsoran pada dinding sumur. Akibat dinding sumur longsor tersebut, ditemukan benda-benda aneh menempel disekeliling dinding sumur yang dicurigai sebagai bekas bangunan. Benda-benda tersebut terkubur sekitar satu setengah meter di bawah permukaan tanah. Setelah dilaporkan ke Dinas kebudayaan oleh pemilik tegalan A.A Ngurah Sentanu.sebagai tindak lanjut dari laporan ini Balai Arkeologi Denpasar segera melakukan survey dan ekskavasi secara bertahap. Situs ini telah disurvey dan diekskavasi dalam 6 tahapan sejak November 1994 sampai 2000.(2) Situs Candi Budha di Desa kalibukbuk disurvey dan diekskavasi dalam 6 tahapan sejak November 1994 sampai 2000 (Astawa, 1994, 2006) dan dilanjutkan dengan studi dan upaya konservasi oleh BPCB Bali. Setelah studi itu dilakukan dilanjutkan dengan studi teknis arkeologi yang dilakukan oleh BP3 Bali Wilayah Kerja Provinsi Bali, NTB, dan NTT pada tahun 2002.Sedangkan pemugarannya berlangsung tahun 2004-2009. Hasil pemugaran ditemukan Candi Budha memiliki banyak keunikan. (3) Hal yang dilakukan dalam pelestarian Candi Budha adalah meningkatkan sumber daya manusia, menyediakan pemandu candi, promosi tentang Candi Budha Kalibukbuk serta peningkatan sarana dan prasarana candi. Candi Budha sebagai representasi komunikasi bahwa umat Budha baik secara personal maupun kelompok masyarakat yang ditandai melakukan doa-doa untuk mendapat pencerahan.

Kata Kunci: Keunikan, sejarah, pelestarian komunikasi, Candi Budha 
Jurnal Widya Sastra Pendidikan Agama Hindu, Vol 4, No. 2, 2022

ISSN: 2656-7466

\author{
KEUNIKAN CANDI BUDHA DAN UPAYA PELESTARIANNYA \\ OLEH: \\ Ketut Suka \\ ketutsuka382@gmail.com \\ I Wayan Gara \\ iwayan.gara@gmail.com
}

\title{
ABSTRACT
}

His study aims to determine the history of the discovery of the Kalibukbuk Buddhist Temple, the process of Restoration and Uniqueness of the Kalibukbuk Buddhist Temple, and to determine the role of the community in efforts to preserve the Kalibukbuk Buddhist Temple.

This research was conducted at the Kalibukbuk Buddhist Temple which is located in Kalibukbuk Village, Banjar Dinas Kalibukbuk, with in-depth observations and interviews with both the owner of the Kalibukbuk Buddhist Temple location, the guards of the Kalibukbuk Buddhist Temple and the community around the Kalibukbuk Buddhist Temple and then the data were analyzed by processing the research findings has been transcribed through a data reflection process, where data is collected and filtered and then compiled again, presented, verified or a conclusion is made.

The results showed several things: (1) The discovery of Kalibukbuk Temple began in 1991, then the process continued again when a resident named I Nengah Mawa in 1994 while draining a well, an avalanche occurred on the well wall. As a result of the landslide, strange objects were found around the walls of the well suspected of being a former building. The objects are buried about one and a half meters below ground level. After being reported to the Culture Service by the owner of the moor, A.A Ngurah Sentanu, as a follow-up to this report, the Denpasar Archaeological Center immediately conducted a survey and excavation in stages. This site has been surveyed and excavated in 6 stages from November 1994 to 2000. (2) The Buddhist temple site in Kalibukbuk village was surveyed and excavated in 6 stages from November 1994 to 2000 (Astawa, 1994, 2006) and continued with studies and conservation efforts by BPCB Bali. After the study was carried out, it was continued with a technical archaeological study conducted by BP3 Bali for the Provinces of Bali, NTB, and NTT in 2002. While the restoration took place in 2004-2009. The results of the restoration found that the Buddhist temple has many unique features. (3) Things to do in the preservation of Buddhist temples are increasing human resources, providing temple guides, promoting Kalibukbuk Buddhist temples and improving temple facilities and infrastructure. The Buddhist temple is a communication representation that Buddhists, both personally and in community groups, are marked by praying for enlightenment.

Keywords: The unique, history, preservation, communication, and Buddhist Temple of Kalibukbuk. 
Jurnal Widya Sastra Pendidikan Agama Hindu, Vol 4, No. 2, 2022

ISSN: 2656-7466

\section{PENDAHULUAN}

Pulau Bali memiliki julukan sebagai pulau seribu pura dan menjadi pulau dengan mayoritas penduduk beragama Hindu. Di samping memiliki seribu pura, pulau Bali juga memiliki banyak peninggalan sejarah, baik yang berupa bangunan (candi, benteng pertahanan), artefak, kitab sastra, dan lain-lain. Peninggalan sejarah merupakan warisan budaya masa lalu yang merepresentasikan keluhuran dan ketinggian budaya masyarakat. Peninggalan sejarah yang tersebar di seluruh pulau Bali merupakan kekayaan budaya yang harus dijaga dan dilestarikan eksistensinya. Dengan adanya peninggalan sejarah, maka Bali dapat belajar dari kekayaan budaya masa lalu untuk menghadapi tantangan dalam kehidupan berbangsa dan bernegara pada saat ini dan masa yang akan datang.

Pemerintah Bali menyadari bahwa peninggalan sejarah merupakan warisan budaya yang memiliki nilai historis. Peninggalan sejarah yang tersebar di seluruh wilayah Bali harus dijaga dan dilestarikan agar nilai-nilai luhur budaya Bali tetap terpelihara.Untuk melindungi benda-benda peninggalan sejarah yang menjadi kekayaan budaya tersebut.

Pemerintah mengeluarkan Undang-undang No 5 Tahun 1992, dan PP No 10 Tahun 1993 sebagai pedoman pelaksanaan undang-undang tersebut.UU No. 5 Tahun 1992 merupakan penyempurnaan dari produk hukum sebelumnya yaitu Monumenten Ordonantie Nomor 21 Tahun 1934 (Staatsblad Tahun 1934 Nomor 515). Dalam UU No. 5 Tahun 1992 yang dimaksud dengan benda cagar budaya adalah: benda buatan manusia, bergerak atau tidak bergerak yang berupa kesatuan atau kelompok, atau bagian-bagian atau sisa-sisanya, yang berumur sekurangkurangnya 50 tahun, atau mewakili masa gaya yang khas dan mewakili masa gaya sekurang-kurangnya 50 tahun, serta dianggap mempunyai nilai penting bagi sejarah, ilmu pengetahuan, dan kebudayaan; benda alam yang dianggap mempunyai nilai penting bagi sejarah, ilmu pengetahuan dan kebudayaan (UU No. 5 Tahun 1992 Pasal 1). Sedemikian pentingnya benda-benda peninggalan sejarah bagi perkembangan dan kemajuan bangsa sehingga pemerintah bertekad untuk menjaga dan melestarikannya.

Candi merupakan sebuah peninggalan bangunan keagamaan yang menjadi tempat ibadah pada jaman beradaban Budha.Candi juga merupakan bangunan agama Bhuda yang memiliki nilai budaya tinggi. Didalam bangunan candi akan ditemukan ukiran serta pahatan yang umumnya diserta relief.

Candi juga merupakan bangunan bersejarah yang dibangun pada saat itu sebagai simbol budaya,agama dan peradaban. Arsitektur dalam bangunan candi dirancang dengan detail yang menggunakan seni tingi dengan ciri-ciri :

1. Candi Budha digunakan sebagai tempat ibadah

2. Candi memiliki sebuah struktur berlapis seperti kamadhatu, Arupadhatu dan Rupadhatu

3. Dibagian atas candi merupakan stupa tanpa rahang bawah,kemudian dilengkapi dengan makara ganda di sisi pintu

4. Candi memiliki relief yang menggambarkan cerita

5. Candi biasanya memiliki patung budha

6. Candi utama terletak di tengah-tengah beberapa candi yang kecil

7. Di pintu kuil ada kala,yang mulutnya terbuka

Dalam Candi Budha, salah satu cirri yang utama adalah struktur candi yang terbagi dalam tiga bagian yaitu :

1. Arupadhatu 
Merupakan struktur terbesar pada candi, terdapat pada bagian atas yang digunakan sebagai symbol bagi orang-orang yang tidak memiliki ketertarikan dan keinginan.Arupadhatu berbentuk stupa yang berisi rongga sebagai patung Budha.

2. Kamadhatu

Merupakan struktur terendah yang melambangkan dunia manusia.

3. Rupadhatu

Merupakan struktur pusat yang melambangkan symbol dunia bebas dari nafsu.Biasanya digambarkan dengan symbol jembatan alam atas dengan yang lebih rendah. Reliefnya menggambarkan kegiatan mengajar Buddha di taman lumbiri.

Bila persepsi masyarakat tentang candi masih mengangap candi sebagai makam, maka hal ini akan berpengaruh terhadap tingkah laku mereka seperti takut berbuat hal-hal yang terlarang dalam candi supaya tidak terkena waladnya, selalu memasang sesaji dan sebagainya.

Sebaliknya apabila persepsi masyarakat tentang candi menganggap candi sebagai tempat rekreasi biasa dimana orang boleh berbuat apa saja tanpa ada norma-norma atau aturan tertentu maka persepsi ini akan mengancam kelestarian candi. Lebih berbahaya lagi apabila masyarakat sekitar candi tergiur untuk mendapatkan uang dengan mencuri arca dari candi untuk dijual kepada orang yang memesannya.

Candi Buddha yang berlokasi di Desa Kalibukbuk merupakan candi yang secara khusus dulunya ditujukan sebagai temapt ibadah umat Buddha di Bali Utara.Struktur Candi Buddha terbuat dari batu bata tanah liat.Komplek bangunan candi terlihat begitu asri dan tertata.

Masyarakat memfungsikan bangunan candi sebagai tempat ibadah sehingga para wisatawan yang datang ke lokasi Candi berniat untuk sembahyang.Menariknya lagi, mereka yang melangsungkan ibadah disini bukan hanya umat Buddha, tetapi juga umat Hindu.Bahkan dibuatkan piodalan yang dilakukan 2 kali dalam setahun, yaitu pada saat Hari Saraswati dan Hari Waisak.

Candi Buddha memiliki arti yang sangat penting bagi perkembangan masyarakat Bali Utara, karena dapat mengembangkan rasa dan nilai toleransi yang tinggi.Candi ini juga memiliki peran startegis bagi perkembangan sejarah Hindu Buddha di Bali.

\section{METODE}

Rancangan penelitian yang digunakan dalam penelitian ini yaitu rancangan penelitian deskriptif kualitatif. Subjek penelitian ini adalah masyarakat sekitar candi budha kalibukbuk, sementara yang menjadi objek penelitian adalah Keunikan Candi Budha Kalibukbuk serta upaya pelestariannya. Metode pengumpulan data adalah observasi, wawancara,dokumentasi dokumen dan kuisioner. Data yang terkumpul dianalisis dengan menggunakan pengolahan data kualitatif dengan langkah-langkah (1) Reduksi Data, (2) Data Display, (3) Kesimpulan atau Verifikasi, (4) Conclucion Drawing/Verifying.

\section{HASIL DAN PEMBAHASAN}

\section{PROFIL DESA KALIBUKBUK}

Desa Kalibukbuk terletak di pinggir pantai yang ombaknya tenang sepanjang tahun, kurang lebih 10 kilometer di sebelah Barat kota Singaraja. Ada dua jalan yang bisa dilalui bila kita hendak mengunjungi desa Kalibukbuk dari arah kota Singaraja. Kepertama kita bisa melalui jalan baru (marga anyar) ke arah Barat.Setelah menempuh jarak kurang lebih $10 \mathrm{~km}$ yang pertama dijumpai adalah desa Kalibukbuk 
Jurnal Widya Sastra Pendidikan Agama Hindu, Vol 4, No. 2, 2022

ISSN: 2656-7466

itu. Jalan atau marga anyar ini dibuat dengan cara terencana pada jaman Belanda, konon selesai tahun 1902.

Kedua, untuk sampai ke desa kalibukbuk bisa juga melalui jalan pedesaan atau marga buwuk melalui desa-desa Baktiseraga, Pemaron, Tukadmungga, Anturan dan sampailah di desa Kalibukbuk. Marga buwuk ini sudah ada sejak jaman dahulu.

Pusat desa Kalibukbuk ditandai dengan persimpangan jalan lima-arah atau "simpang lima".Desa Kalibukbuk yang kita lihat sekarang ini sudah berbeda dengan keadaan pada masa lampau, katakanlah duapuluh tahun yang lalu.Waktu itu penduduknya hidup secara tradisional dari pertanian seperti kelapa (kopra) dengan beternak sapi, kerbau, babi, ayam bebek dan sebagainya.Di samping itu mereka juga ada yang bekerja di sawah.Diantaranya ada yang hidup sebagai nelayan, ada juga sebagai buruh atau tukang bangunan.

Itu dahulu.Tetapi sekarang desa Kalibukbuk adalah desa yang sudah menjadi tempat tujuan wisata yang cukup terkenal di mancanegara. Hal ini dapat kita lihat dengan telah tercantumnya nama desa Kalibukbuk di banyak buku panduan wisata (guide book) di dalam dan di luar negeri. Bahkan di internet sudah banyak disebutkan desa Kalibukbuk ini.

Mungkin masih ada di antara kita yang belum mengetahui bagaimana proses transformasi ini berlangsung dan keterlibatan masyarakatnya, dari masyarakat tani ke arah pariwisata. Dimulainya dengan suatu rintisan atau terobosan yang dilakukan oleh warga desa sebagai yang diuraikan di halaman lain situs ini, maka setelah itu kepariwisataan berkembang bersama-sama dengan lima desa tetangganya membentuk satu kawasan wisata. Pembangunn sarana pariwisata sekarang ini masih terus berlangsung seperti tidak mengenal kata mengaso.

Apa yang dipaparkan diatas adalah suatu kenyataan yang kita bisa lihat secara "sekala". Dari seorang pengamat mungkin mengatakan, memang "sejarah selalu mengulangi dirinya" (history repeats itself). Namun di antara masyarakat sendiri terutama yang memandangnya dari sudut religius sering menghubungkan keadaan ini dengan pengaruh "niskala". Bahwa ada sebab di balik akibat.Bahwa ada energi spiritual yang berpotensi.Bahwa ada yang menyebut desa Kalibukbuk "ketakson', ke-elingin oleh para leluhur. Sudah merupakan pituduh sang meduwe jagat.

Sebenarnya, Orang-orang tua dulu menyebut desa ini dengan nama Tanah Gesar. Tetapi sekarang nama Tanah Gesar jarang terdengar kecuali kalau disebut oleh kalangan orang-orang tua. Yang lebih sering dipakai adalah nama Kalibukbuk. Ada sementara orang yang mengkaitkan nama Kalibukbuk dengan Kalingga, sebuah nama kota di India.

Namun perlu disebutkan juga disini adanya ceritra rakyat atau legenda yang menceritakan bahwa jaman dahulu Kerajaan Tanah Gesar (Kalibukbuk) dikalahkan oleh sejenis ikan laut yang disebut ikan bano yang berparuh lancip seperti anak panah.Banyak anggota masyarakat yang terbunuh dipantai yang membuat rakyat resah dan menjauhi pesisir pantai.Lalu Raja waktu itu berupaya menolong rakyatnya dengan mengadakan sayembara.Datanglah seorang pemuda yang menyatakan kesanggupannya untuk mengalahkan ikan bano tersebut dengan imbalan minta sebagian wilayah Tanah Gesar.Raja pun setuju.Memang benar pemuda itu bisa mengalahkan ikan-ikan bano tersebut.Tetapi Raja malahan berbalik pikiran, pemuda itu dibunuh.Tidak lama kemudian datang semut ribuan banyaknya menyerang Raja dan rakyatnya.Akhirnya semua penduduk meninggalkan tempat itu dan membuat 
Jurnal Widya Sastra Pendidikan Agama Hindu, Vol 4, No. 2, 2022

ISSN: 2656-7466

Tanah Gesar tinggal dalam kesunyian. Itu hanyalah ceritra rakyat biasa yang bersifat dongeng.

Rupanya memang benar desa Tanah Gesar atau Kalibukbuk ini mengandung misteri.Mungkin sebahagian kulitnya sudah bisa terungkap, namun masih banyak yang masih perlu ditelusuri selanjutnya.Yang sangat mentakjubkan dan juga cukup mengemparkan adalah temuan situs arkeologi pada tahun 1994.Bangunan peninggalan sejarah tersebut berupa Candi Budha diperkirakan peninggalan abad ke 11. Candi tersebut tertimbun sekitar dua meter di bawah permukaan tanah, ditemukan di tengah-tengah tegalan milik warga di wilayah desa Kalibukbuk berdekatan dengan Pura Bukit Sari. Setelah diadakan survey lalu dilakukan ekskavasi oleh Balai Arkeologi selama enam tahun yaitu sampai tahun 2000.Sekarang situs tersebut berada dalam penanganan Balai Pelestarian Peninggalan Purbakala.Perlu dicatat tidak jauh dari tempat itu, pernah juga ditemukan peninggalan berupa kerangka manusia dari jaman lampau tertanam di dekat pantai.

Dengan temuan sejarah tersebut maka sedikitnya terungkap bahwa Kalibukbuk cukup kaya akan kandungan sejarah. Semua itu menunjukkan bahwa sudah sejak jaman pra sejarah wilayah Kalibukbuk ini sudah dikenal.Rupanya juga, jaman itu pantainya merupakan pelabuhan laut yang menghubungkan daratan pulau Bali dengan dunia luar.Bila memang demikian maka sudah sejak jaman dahulu desa Kalibukbuk dikunjungi oleh orang-orang dari seberang lautan dengan pengaruh bermacam budaya silih berganti.

Setelah itu wilayah Kalibukbuk seperti tak bertuan.Tanah di pesisir pantai Kalibukbuk ini banyak di kuasai oleh pendatang, seperti suku Bugis dan orang Melayu.Kemudian bangsa Eropa seperti Inggris dan Belanda mulai mengincar pulau Bali untuk mencari tanah jajahan sehingga mengakibatkan makin runyamnya situasi.Pergolakan mulai terjadi di Bali Utara, dimana raja Buleleng beserta rakyat menentang kedatangan kaum penjajah.Rakyat Buleleng pun terus bertempur melawan tentara kolonial Belanda yang memuncak dengan perang Jagaraga tahun 1846-1849.Sedangkan pada waktu berkecamuknya perang Banjar tahun 1868 desa Kalibukbuk seperti ditinggal sebagian besar penghuninya.

A. Struktur Pemerintahan Desa Kalibukbuk
a. Kepala Desa
: Ketut Suka
b. Sekretaris desa
: Putu Agus Ariawan, S.e
c. Kepala Seksi Kesra
: I Made Sumadana
d. Kepala Seksi Pemerintahan
: I Made Arnata
e. Kepala Seksi pelayanan : I Gede Adnyana
f. Kepala urusan TU dan umum : Ketut Suwartana
g. Kepala urusan perencanaan : Ni Ketut Marhaeni
h. Kepala Urusan Keuangan : Putu Lisa Swandewi, S.Pd
i. Kelian Banjar Dinas :

1. Kelian Banjar Dinas Kalibukbuk

: I Gede Suarjana, S.E

2. Kelian Banjar Dinas Banyualit

: Made Suwitna

3. Kelian Banjar Celuk Buluh

: Putu Suardika, S.Pd

Batas Wilayah Desa Kalibukbuk

Desa Kalibukbuk terdiri dari 3 Banjar Dinas yaitu :

1. Banjar Dinas Kalibukbuk

2. Banjar Dinas Banyualit

3. Banjar Dinas Celuk Buluh. 
Jurnal Widya Sastra Pendidikan Agama Hindu, Vol 4, No. 2, 2022

ISSN: 2656-7466

Kemudian, Desa Kalibukbuk memiliki wilayah yang cukup luas dengan batas -batas sebagai berikut :

1. Sebelah Utara berbatasan dengan laut Bali

2. Sebelah Selatan berbatasan dengan Desa Kayuputih

3. Sebelah Timur berbatasan dengan Desa Anturan

4. Sebelah Barat berbatasan dengan Desa Kaliasem.

Luas Desa kalibukbuk adalah 295,025 ha/m2

Jumlah penduduk 7.945 jiwa

\section{SEJARAH PENEMUAN CANDI BUDHA KALIBUKBUK}

Penemuan Candi Kalibukbuk bermula pada tahun 1991 diawali dengan fenomena penemuan beberapa stupika saat pengelola Hotel Angsoka melakukan penggalian tanah untuk pembuatan kolam. Dari penemuan ini, para pekerja mendapatkan sebanyak 80 stupika, 3 relief, serta 18 materai yang kesemuanya tersimpan di Balai Arkeologi Denpasar.

Fenomena tersebut kembali terjadi pada tahun 1994 saat penyakap atau penggarap tanah ingin memperbaiki sumur yang jebol beberapa kali.Tanpa rasa curiga, pengalian dilakukan.Namun pada saat penggalian ditemukan reruntuhan dan longsoran dinding sumur serta terlihat adanya benda-benda yang ternyata adalah batu bata yang merupakan bekas reruntuhan dari Candi Budha Kalibukbuk.Kemudian hal tersebut dilaporkan kepada pemilik tanah yaitu A.A Ngurah Sentanu. Kemudian oleh A.A Ngurah Sentanu dilaporkan ke Dinas kebudayaan. Sebagai tindak lanjut dari laporan ini Balai Arkeologi Denpasar segera melakukan survey dan ekskavasi secara bertahap. Situs ini telah disurvey dan diekskavasi dalam 6 tahapan sejak November 1994 sampai 2000 (Astawa, 1994, 2006) dan dilanjutkan dengan upaya konservasi oleh BPCB Bali.

\section{PROSES PEMUGARAN DAN KEUNIKAN CANDI BUDHA KALIBUKBUK Proses Pemugaran}

Situs Candi Budha di Desa kalibukbuk disurvey dan diekskavasi dalam 6 tahapan sejak November 1994 sampai 2000 (Astawa, 1994, 2006) dan dilanjutkan dengan studi dan upaya konservasi oleh BPCB Bali. Setelah studi itu dilakukan dilanjutkan dengan studi teknis arkeologi yang dilakukan oleh BP3 Bali Wilayah Kerja Provinsi Bali, NTB, dan NTT pada tahun 2002.Sedangkan pemugarannya berlangsung tahun 2004-2009

Pemugaran Candi menghabiskan waktu sekitar 5 tahun karena mereka harus berhati-hati dalam menyususn batu - batu bertulis motif sulur-suluran, relief gajah dan gana yang merupakan bagian dari candi, 100 stupika, serta susunan batu andesit.

Sesuai hasil pemugaran, maka didapatkan hasil bangunan Candi Induk atau Utama berbentuk segidelapan dengan diameter $8 \mathrm{~m}$ dan panjang tiap sisinya 3 meter.Di tengah-tengah dasar candi terdapat struktur batu andesit yang menjari ke delapan arah mata angin.Diperkirakan terdapat satu buah bilik atau ruangan candi pada bangunan utama ini. Hal tersebut diperkuat oleh temuan fitur berupa lantai dari tanah merah (batubata yang dihaluskan) pada tengah candi dan tangga masuk di sebelah tenggara.Pada badan candi kemungkinan terdapat relief-relief budha, gana, gajah, padma dan sulur-sulur yang dipahatkan pada setiap sisi dinding dengan batas bingkai (frame). Keseluruhan bentuk tersebut ditemukan pada saat penggalian baik oleh Balar Denpasar maupun BP3 Pejeng.Setelah Candi Budha selesai dipugar, maka dilakukan upacara Pemelaspas yang kegiatan Upakaranya menggunakan 
Jurnal Widya Sastra Pendidikan Agama Hindu, Vol 4, No. 2, 2022

ISSN: 2656-7466

tatacara Hindu. Berikut ini merupakan proses pemelaspas dan peresmian Candi Budha Kalibukbuk

\section{Keunikan Candi Budha Kalibukbuk}

Keunikan Candi Budha Kalibukbuk terletak pada struktur dan relief Candi.Struktur diidentifikasikan sebagai susunan terhadap sesuatu hal.Susunan ini dapat dianalisis secara vertical maupun secara horizontal. Hamper setiap benda memiliki struktur, yaitu susunan unsur-unsur yang ada dalam benda tersebut. (Priyono: 2007,3) hal tersebut dipertegas lagi oleh (Yudiata,55) yang menyatakan bahwa struktur atau konstruksi merupakan suatu teknik untuk memasang batu-batu ) padas, karang laut, citakan dan sebagainya) secara tradisional menghindari pemakaian perekat yang kemudian diisi relief ragam hias pepahatan dan pepalihan secara tradisional dibentuk dengan pengolahan material bebatuannya. Dalam pembentukan struktur dan relief biasanya disesuaikan antara kontruksi dengan karakter materialnya.).

Keunikan dari candi Budha kalibukbuk yang pertama adalah (1) Kompleks Candi Kalibukbuk menghadap ke arah tenggara.Biasanya arah candi menghadap ke utara.Sementara Candi Budha menghadap ketenggara hal ini dapat diketahui karena pada induk candi terdapat tangga yang berada di sisi tenggara, (2) Keunikan Kedua, biasanya relief candi menggunakan relief cerita pewayangan, dengan mengambil alur cerita Ramayana dan patung Dewa yang secara umum yaitu Siwa ataupun Wisnu.Tetapi pada peninggalan Candi Budha dihias dengan motif sulursuluran dan relief Ghana dengan posisi jongkok, kedua tangan diangkat ke atas di samping kepala seperti posisi menahan beban di atasnya.Dari sisa-sisa unsur dekoratif tersebut menghasilkan rekontruksi bentuk candi utama berupa stupa dihias dengan relief Ghana berada di antara lantai hiansan relief dan bagian atas kaki candi, (3) Keunikan candi Budha yang beikutnya adalah berbentuk stupika dengan sudut-sudut simetris yang sangat jelas.Kemudian ada batu- batu kecil yang menyerupai sebuah pagar yang hanya terdiri dari sebuah batu saja. Padahal biasanya Candi itu berbentuk stupika dengan garis yang hampir tidak Nampak sama sekali, (4) Disebelah candi Budha terdapat pohon kelapa yang tidak umum ditemukan pada wilayah lain. Menurut masyarakat sekitar, pohon kelapa itu disebut dengan Pohon Kelapa Rangda, karena ranting bakal buah yang dalam Bahasa bali disebut pangan dan kloping tumbuh dari sebagian batangnya, demikian pula memiliki daun yang sangat lebat dan sangat kuat. Bahkan daun, kloping maupun pangan yang sangat keringpun sangat sulit untuk jatuh karena sangat kuatnya.Kelapa ini sangat sulit berbuah, jikapun berbuah biasanya hanya sebutir atau dua butir dan tidak pernah jatuh.Menurut kepercayaan masyarakat setempat, buah dan daun dari pohon kelapa ini memiliki kegunaan untuk kegiatan yang memiliki nilai magic, (5) Seperti dijelaskan bahwa candi Budha bangunan yang menghadap kearah tenggara, hal ini sangat berkaitan dengan kemudian dibangunnya pelinggih Majapahit yang berlokasi diarah tenggara dari candi Budha ini. Hal tersebut membuktikan bahwa ada kaitan yang sangat erat antara camdi Budha dengan PuraMajapahit yang menurut kesaksian dari Kelian Desa adat menyatakan bahwa, Pura Majapahit itu sebenarnya ingin dibangun diwilayah Denpasar dan tempat lain, tetapi pengempon Pura mendapat pawisik agar membangun Pura Majapahit di lokasi saat ini, yaitu berdekatan dari candi Budha dan berada diarah Tenggara sesuai dengan arah dari Candi Budha tersebut

\section{UPAYA PELESTARIAN DAN REPRESENTASI CANDHI BUDHA KALIBUKBUK}


Jurnal Widya Sastra Pendidikan Agama Hindu, Vol 4, No. 2, 2022

ISSN: 2656-7466

\section{Upaya Pelestarian}

Upaya yang akan dilakukan masyarakat untuk memanfaatkan Candi Budha Kalibukbuk sebagai sumber daya budaya pada masa kini meliputi: (1) Masyarakat mempromosikan melalui akun media social tentang keberadaan Candi Budha Kalibukbuk. Hal ini bertujuan agar keberadaan Candi Budha Kalibukbuk dikenal di Indonesia maupun secara Internasional sehingga dapat menarik minat wisatawan asing untuk datang melihat keunikan Candi Budha Kalibukbuk, (2) Adanya beberapa pedagang yang berjualan dekat dengan Candi Budha, hal tersebut bertujuan memudahkan pengunjung dalam mendapatkan keperluan sembahyang, makan dan minum setelah mereka selesai berkunjung ke candi Budha, (3) Menjaga kebersihan dan kenyamanan lingkungan sekitar candi, sehingga Candi Budha terjaga kebersihan dan keindahannya, hal tersebut bertujuan agar pengunjung, utamanya Umat Budha yang dating untuk bersembahyang mendapat kenyamanan dalam melakukan kegiatan sembahyang, (4) Melakukan gotong royong pembersihan sepanjang jalan menuju Candi yang bertujuan tercipta kenyamanan dan keindahan dijalan menuju Candi Budha, (5) Candi Budha juga sering dijadikan sebagai media pembelajaran sejarah oleh beberapa sekolah yang letaknya berdekatan dengan lokasi Candi Budha, sehingga siswa menjadi lebih nyata dalam melihat dan mengamati bangunan Candi Budha

\section{Representasi Candi Budha Kalibukbuk}

Candi Budha merupakan bentuk representasi komunikasi dari Umat Budha dalam pemujaan terhadap Sang Budha dalam hubungan yang personal antara Umat Budha dengan Sang Budha untuk menghindarkan diri dari sifat Akusala Mula3 serta mencapai sifat Ovada 3 untuk kemudian menuju penghentian samsara dan mencapai pencerahan dari Sang Budha.

Sebenarnya inti dari pemujaan terhadap Sang Budha memiliki tujuan utama yitu tidak melakukan segala bentuk kejahatan, senantiasa mengembangkan kebajikan dan membersihkan batin, terlepas dari samsara atau penderitaan dan mendapat pencerahan dari Sang Budha (Dhammapada:183).

Dari uraian tersebut dapat dijelaskan bahwa pemujaan umat Budha terhadap Sang Budha dapat menciptakan hubungan spiritual dalam ikatan batin yang sangat kuat didalam hati Umat Budha untuk dapat melakukan tindakan-tindakan seperti apa yang dilakukan oleh Sang Budha untuk terhindar dari segala bentuk kejahatan serta penderitaan untuk kemudian mendapat pencerahan dari Sang Budha dengan memiliki sifat welas asih dan mengembangkan kebajikan dalam kehidupan.

\section{DAFTAR PUSTAKA}

Aksara. Brown, Douglas. 2008. Prinsip Pembelajaran dan Pengajaran Bahasa. California.

Alwasilah,Adeng Chaedar. 2008. Filsafat Bahasa dan Pendidikan. Bandung. Remaja Rosdakarya.

Alma, Buchari. 2009. Guru Profesional Menguasai Metode dan Terampil Mengajar, Bandung: Alpabeta.

Arikunto, Suharsimi. 2006. Prosedur Penelitian Suatu Pendekatan Praktik, Jakarta: Bumi.

Bungin, Burhan. 2008. Sosiologi Komunikasi (Teori, Paradigma dan Diskursus

Teknologi Komunikasi di Masyarakat), Jakarta : Kencana

Citra,Irwan, 2015. "Perkembangan Tatanan Massa dan Ruang Arsitektur Candi di Jawa", Skripsi Universitas Katolik Prarahyangan, Bandung. 
Jurnal Widya Sastra Pendidikan Agama Hindu, Vol 4, No. 2, 2022

ISSN: 2656-7466

Departemen Pendidikan Nasional. 2003. Undang-Undang Republik Indonesia (UU RI) Nomor20 tahun 2003 Tentang Sistem Pendidikan Nasional, Jakarta: Depdiknas.

Foss, Karen A, Littlejohn, Stephen W. 2012. Teori Komunikasi Theories of Human Communication, Jakarta: Salemba Humanika.

Hafied Canggara, Hafied,H.2004. Pengantar Ilmu Komunikasi, Jakarta : PT. Raja Grafindo Persada.

Halim,Andre,2016, "Makna Ornamen pada Bangunan Candi Hindu dan Buddha di Pulau Jawa", Skripsi Universitas Katolik Prarahyangan,Bandung

Larson, Goldberg-Carl, Alvin A. E. 2006. Komunikasi Kelompok Proses Diskusi dan Penerapanya, Jakarta : Universitas Indonesia Press.

Muhammad, Arni 2002 Komunikasi Organisasi, Jakarta: Bumi Aksara.

Muhammad,Arni 2005. Komunikasi Organisasi, Jakarta: Bumi Aksara.

Mulyana,Deddy.2004. Ilmu Komunikasi: Suatu Pengantar, Bandung: Remaja

Rosdakarya.

Moleong, Lexy J.. 2007. Metodologi Penelitian Kualitatif, Bandung: Remaja

Rosdakarya.

Onong, Uchjana Effendy, 2007. IImu Komunikasi Teori dan Praktek, Bandung: PT.

Remaja Rosdakarya.

Poloma, Margaret. 2013. Sosiologi Kontemporer, Jakarta: PT. Raja Grafindo Persada.

Ranjabar, Jakobus. 2006. Sistem Sosial Budaya Indonesia. Bogor :Ghalia Indonesia Ritzer, George .2010. Teori Sosisologi Modern, Jakarta: Kencana.

Rosdakarya.

Khaeruddin dan Mahfud Junaedi. 2007. Kurikulum Tingkat Satuan Pendidikan.

Roudhonah, 2007. IImu Komunikasi, Jakarta: UIN Jakarta Press.

Santyasa, I Wayan. 2008. Pembelajaran Berbasis Masalah dan Pembelajaran

Kooperatif, Bali: Universitas Pendidikan Ganesha

Sugiyono. 2007. Metode Penelitian Kuantitatif Kualitatif dan R \& D, Bandung: Elfabeta

Sutopo H.B.. 2006. Metodologi Penelitian Kualitatif, Surakarta: Universitas Negeri

Sebelas Maret.

Tohirin, Metode Penelitian Kualitatif,.Jakarta :Rajagrafindo Persada

Wiana, I Ketut, 2003:7.Pelinggih Merajan, Denpasar:Upadasastra

Widjaja, AW. 1986. Komunikasi dan Hubungan Masyarakat, Jakarta: Bina Aksara.

Winanti, Ni Putu, 2009: Pura Keluarga dan Pratima, Denpasar.Pustaka Bali Post.

Wirawan, I.B. 2012. Teori-Teori Sosial Dalam Tiga Paradigma (Fakta Sosial, Definisi

Sosial Dan Perilaku Sosial), Jakarta, Kencana Prenadamedia Group.

Wulansari,Dewi. 2009. Sosiologi: Konsep dan Teori, Bandung: PT. Rafika Aditama. 